\title{
Importancia de la educación en humanidades para el ámbito laboral: percepción de las personas egresadas de una universidad peruana
}

Cervera Vallejos, Mirtha Flor; Reluz Barturén, Francisco Felizardo

Importancia de la educación en humanidades para el ámbito laboral: percepción de las personas egresadas de una universidad peruana

Revista Educación, vol. 43, núm. 2, 2019

Universidad de Costa Rica, Costa Rica

Disponible en: http://www.redalyc.org/articulo.oa?id=44058158044

DOI: https://doi.org/10.15517/revedu.v43i2.32110

Esta obra está bajo una Licencia Creative Commons Atribución-NoComercial-SinDerivar 3.0 Internacional. 


\title{
Importancia de la educación en humanidades para el ámbito laboral: percepción de las personas egresadas de una universidad peruana
}

\author{
The Importance of an Education in Humanities for Employment: Perception of Graduates from a Peruvian \\ University
}

Mirtha Flor Cervera Vallejos

Universidad Católica Santo Toribio de Mogrovejo, Perú mcervera@usat.edu.pe

iD http://orcid.org/0000-0002-4972-1787

Francisco Felizardo Reluz Barturén

Universidad Católica Santo Toribio de Mogrovejo, Perú

freluz@usat.edu.pe

iD http://orcid.org/ 0000-0002-8951-1143

\author{
DOI: https://doi.org/10.15517/revedu.v43i2.32110 \\ Redalyc: http://www.redalyc.org/articulo.oa?id=44058158044
}

Recepción: 31 Enero 2018

Aprobación: 27 Junio 2019

\section{Resumen:}

Actualmente a los saberes humanísticos se les relega en la formación profesional, debido al predominio científico-tecnológico; sin embargo, es sabido que la universidad también debe preparar integralmente al futuro y la futura profesional que la sociedad requiere. Este artículo es consecuencia de investigación cualitativa con abordaje de grupos focales que buscó describir y analizar la educación de las humanidades en el ámbito laboral desde las percepciones de las personas egresadas de una universidad peruana. Se utilizó la entrevista semiestructurada a cuatro grupos focales, integrado por 32 egresados de las diferentes facultades de la universidad estudiada. El muestreo fue intencional y por bola de nieve, hasta obtener saturación. Se procesaron los datos por análisis del discurso de cada participante, los cuales fueron codificados para protección de su identidad. Se concluye que la enseñanza de las humanidades favorece el crecimiento personal social para el campo laboral de las personas egresadas.

Palabras clave: Educación en humanidades, Formación profesional, Competencia profesional.

\section{Abstract:}

Knowledge of the Humanities has become undervalued as part of career preparation given the predominance of Science and Technology. However, it is acknowledged that higher learning institutions must also prepare future professionals comprehensively, as required by society. This article reveals the results of qualitative research with focal groups gathered to discuss their perceptions about graduates from a Peruvian University the need of education in the humanities to future graduates. The semi-structured interviews were conducted with the four focal groups. The groups were composed of 32 graduates from the universities involved in the study. Sampling was intentional and with a snowball effect until saturation was obtained. Data was processed based on analysis of each participant's discourse which was coded to protect their identity. It was concluded that teaching about the Humanities fosters personal social growth, particularly among graduates who will one day join the work force. KEYWORDS: Education in the Humanities, Professional Training and Skills Development.

\section{INTRODUCCIÓN}

Actualmente a los saberes humanísticos les dan poco prestigio en una sociedad dominada por la eficacia y rapidez de las nuevas tecnologías. Disciplinas como filosofía, antropología, historia, lengua -que hasta hace bien poco constituían el núcleo de la enseñanza universitaria- han quedado prácticamente abandonadas, tal como lo afirma Stramiello (2005), o como lo asume Vargas (2010) al decir que en los Estados Unidos subyace un reduccionismo en la concepción de la persona y su dimensión social constitutiva, por lo que 
la naturaleza y la misión de la Universidad asumen posturas excluyentes frente a sus fines esenciales, como rechazar formación humanista o desde una perspectiva de fe.

Hoy se justifica la formación universitaria como instrumento útil para lograr otros fines, afirmándose que es buena para los negocios o para las carreras profesionales, pero es inusual considerarla buena para la persona, en el sentido que le permita conocer la verdad y elegirla en pro de la sociedad para transformarla positivamente. En efecto, como piensa Alvira (2006) unas humanidades que no se ocupan primariamente del ser humano, son un poco extrañas; ya Sócrates, a través de Platón, lo supo decir de modo preciso: lo principal es escribir en las almas, es decir, no solo en lo cognitivo de las personas, sino en su multidimensionalidad.

Infiriéndose la vital importancia para la Universidad la formación de la persona con una visión del mundo integral. Su misión hoy es civilizar al mundo, desde la verdad, el bien y la belleza, refiere Etcheverry (2002, citado por Pizzul (2013). Sin embargo, actualmente la universidad ha perdido su unidad, precisamente porque el rendimiento social de los saberes universitarios es parcial. Pues, Pizzul (2013) afirma que construir la cultura, hacer al ser humano justo, no se considera rentable, ni tampoco como un impulso efectivo para el progreso. Para que la universidad cumpla su misión con respecto de la sociedad futura, es preciso que las humanidades muestren su rendimiento social. Por consiguiente, es actualmente un reto hacer que las humanidades constituyan el fundamento indispensable de la formación especializada de las distintas facultades o departamentos de una universidad.

$\mathrm{Al}$ respecto, en la Universidad Católica Santo Toribio de Mogrovejo [USAT], con 19 años de fundación, tiene 3216 egresados y egresadas hasta el momento de la investigación; constituyéndose en una alternativa relevante para las y los jóvenes del norte y oriente del Perú, quienes tienen en su proyecto de vida la inclusión de una formación personal y profesional con exigencia académica y con sentido ético. De acuerdo al Modelo Educativo de la universidad la prioridad son sus estudiantes (USAT, 2011) cuya finalidad es que sean ciudadanos y profesionales mediante una formación integral. En cuanto Universidad Católica, inspira y desarrolla sus actividades según los ideales, actitudes y principios católicos; manteniendo fidelidad al magisterio, doctrina y moral de la Iglesia Católica refieren los Estatutos (USAT, 2009).

Por ello, promueve entre sus estudiantes la adquisición de una educación que armonice la riqueza del desarrollo humanístico y cultural con la formación profesional científica especializada, que al mismo tiempo desarrolle la capacidad de admiración, de intuición, de contemplación y llegue a ser capaz de formarse un juicio personal y de cultivar no solo el sentido humana y espiritualmente, por lo que existen actividades concretas desarrolladas por los departamentos de Teología- Filosofía y de Humanidades que de modo directo tienen como finalidad esta formación en la comunidad universitaria en las 18 escuelas profesionales.

Cabe mencionar entre ellas, la enseñanza de las Humanidades (ética, bioética, deontología, comunicación, lengua y literatura), la Filosofía y la Teología, las cuales se imparten a los estudiantes de modo transversal en los años de su formación profesional y equivale al 12\% de su malla curricular y con 18 horas académicas. Sumados a la labor de capellanía a través de la pastoral universitaria y la tutoría. Sin embargo, muchas de estas materias humanísticas desarrolladas en todas las escuelas profesionales, a veces son rechazadas por las y los estudiantes porque no logran encontrar su aplicación en el momento de recibirlas, muchos afirman que no les permiten estudiar las asignaturas principales y con mayor crédito, critican a la vez a los profesores y profesoras porque hay mucho que leer y presentar trabajos, otros aluden que la materia se centra en exposiciones.

Entonces cabe plantearse la siguiente pregunta de investigación: ¿Cómo la educación de las humanidades ayuda en el ámbito laboral, según las percepciones de las personas egresadas de una universidad peruana? Para lo cual se plantearon los objetivos: Describir y analizar la educación en humanidades en el ámbito laboral según las percepciones de sus egresados y egresadas. 


\section{MARCO TEÓRICO}

Entre los antecedentes de estudio se tiene a López (2009) quien analizó los efectos de la relación entre educación y empleo de los jóvenes en el mercado laboral considerando que existe una diferencia entre los individuos que están en la ocupación para la que fueron formados y aquellos que no son parte de ese caso, concluyéndose que existe alta correspondencia entre formación y ocupación implicando mejor desempeño y mayores ganancias. Esta investigación contrasta con la postura de Stramiello (2005) quien reflexiona sobre la necesidad actual de ofrecer una educación del ser humano en lo humano, y no solo que se aprenda rápidamente lo que sirva en función de un futuro trabajo.

Una concepción mercantilista de la vida tiende a desvalorizar la cultura y consecuentemente se niega a las y los jóvenes, saberes variados que les permiten desarrollar su humanidad a través del conocimiento de los testimonios que la humanidad ha dejado a lo largo de la historia, por lo que Amarcha, Cristóbal y Castro (2005) piensan que la preocupación de los estudios sobre empleo y mercado de trabajo se centraban en la falta de ajuste entre titulados cualificados y requisitos ocupacionales cada vez mayores, en contraste con una proporción de la población universitaria creciente, noción compartida con Aldana (2009) quien además agrega que en la época contemporánea el estudio de las humanidades ha caído en un desplazamiento, suplantación y olvido injustos.

La investigación de Vargas (2010) elaboró un contraste entre la manera como la tradición clásica o humanista concibe la formación personal y los principios básicos que orientan la formación basada en la calidad y en las competencias evaluando cuáles son las ganancias y pérdidas que lleva consigo el modelo de la cualificación de la educación. El autor explica la pérdida de vigencia de la formación humanística en favor de la denominada formación integral y del énfasis en garantizar la calidad de los procesos institucionales de educación.

Ruiz (2002) piensa que en la actualidad la universidad está ante la tarea de desarrollar un nuevo ethos, que no es igual a un adoctrinamiento moral. El saber de las humanidades es saber de la acción y para la acción, teoría y praxis, esto es, todo comportamiento humano mediado simbólica y lingüísticamente. Por tradición, son las llamadas humanidades las que han de contribuir a esta reflexión, como experiencia de comprensión y de autocomprensión.

Por su parte Martínez (2009) abstrae que sin una sólida educación básica no es posible acceder a los beneficios disponibles por la desregularización del mercado, la privatización y el impulso de la actividad creadora en las empresas, ni siquiera la expansión de las tecnologías de la información y la comunicación, imprescindibles en un desarrollo sostenible; por eso Solís (2010) al evaluar la relación entre distintos tipos de profesionales que demanda el mercado laboral y las habilidades y conocimientos concluye que la influencia de la educación humanista contribuye a la formación del perfil profesional pertinente para la economía basada en el conocimiento.

Desde una fundamentación teórica, la educación es un acto de crecimiento, subrayando que se trata de un crecimiento interior, esto acontece en alumnos y alumnas, y también en las profesoras y profesores. Como el crecimiento interior no tiene tope, el buen uso del tiempo se convierte en algo fundamental para la vida humana; y para sacar el mejor provecho posible a esa temporalidad que es connatural, se cuenta con la ética.

El trabajo con la y el educando es la actividad que se ocupa de manera más directa de la persona. El aula, en esta visión, es concebida como un espacio excepcional para aprender a ser mejor persona, y por ello, el quehacer educativo requiere profesores enamorados y enamoradas de su misión, que estén profundamente convencidos y convencidas de la trascendencia de su labor, por lo que es necesario formar docentes competentes para que descubran y valoren en cada uno de sus alumnas y alumnos sus potencialidades y capacidades refiere Vargas (2010).

La educación es el resultado del conocimiento teórico que se va adquiriendo, del conocimiento práctico que se tiene de la realidad, y del conocimiento que se tiene de sí mismos refiere Martínez (2009) o como lo 
entiende Reluz (2014), siguiendo el pensamiento tomista: la educación es un proceso de perfeccionamiento que dura toda la vida.

Al hablar de las humanidades, no se trata de un saber específico como el derecho, la ingeniería, la comunicación social o la administración de empresas; la palabra hace mención a una pluralidad no reducible al ámbito de una carrera específica. Son saberes que están en una relación dialógica de la cual obtienen su fuerza y proyección. Las humanidades no tienen un objeto específico, tienen que ver de manera especial con cada una de las formas cómo se desarrolla y se ejercita la formación de la inteligencia en la universidad sugiere Solís (2010).

El filósofo español Leonardo Polo (1997) destaca, que las humanidades se constituyen como el bastión de una serie de valores que, aunque carecerían de utilidad práctica, sin embargo son necesarios para otro asunto que sigue siendo importante, a saber, la formación de los seres humanos. O, como lo refiere Llano (1998), la singularidad de las humanidades hay que encontrarla en el modo como ellas toman en consideración el devenir histórico de la acción humana, es decir, el comportamiento de las personas en situaciones concretas.

El saber de las humanidades es un saber de la acción y para la acción. De manera esencial le concierne la comprensión, es decir el modo de ser de la vida humana en cuanto que es poder ser y posibilidad. Para las humanidades, esto quiere decir que lo estudiado por ellas posee siempre un sentido vinculante, algo que afecta y concierne a todas y todos.

Por consiguiente, siguiendo a Sellés (2007), las humanidades ayudan a descubrir la esencia humana en sus diversas facetas. Ayudan a aprender acerca del sentido de lo humano y permite acceder a la intimidad de la persona, situación que permite llegar a conocer a Dios, por vía de interioridad, cuya carencia es drama de este tiempo. Los y las humanistas, afirma el autor, son grandes observadores y penetran admirablemente en los motivos positivos y negativos de las acciones humanas: callan y piensan, y solo hablan cuando han descubierto las razones y cuando vale la pena denunciar los errores para enseñar a los demás a no cometerlos.

Por su parte, Llano (1998) explica que las humanidades se han revelado como la base de actividades profesionales en las que el conocimiento de los caracteres de las personas presenta una importancia esencial en la gestión de recursos humanos.

Por ello, el cúmulo de información y la finura de análisis que ofrecen las humanidades son superiores a las aportaciones de las ciencias sociales puesto que permiten el conocimiento de la persona en su integridad, aunque el camino que es preciso seguir actualmente exige un estrecho acercamiento interdisciplinar. El humanismo agrega Llano, Alvira, Calleja, Bastons y Martínez (1992) citando a Kant, consiste en tratar a la persona no solo como medio, sino como un fin. Todo esto ha de quedar recogido en el humanismo de hoy, y constituye la base de toda comunidad humana justa y, por supuesto, de la empresa.

En este sentido, la formación humanística confiere hondura a las profesiones, así toda actividad profesional vivida con rigor y seriedad presenta una dimensión filosófica, sin la cual pierde su capacidad creativa y se ve abocada a la simple rutina. En consecuencia, la presencia de las humanidades, deben estar en los niveles de la enseñanza media y universitaria, abordándose desde una cuádruple perspectiva: Primero, las humanidades como interpretación crítica de la realidad actual. Segundo, las humanidades como revitalización de la cultura. Tercero, las humanidades como reflexión sobre las grandes cuestiones personales y sociales. Cuarto, las humanidades como catalizadores de la creatividad.

Sin humanidades, los planteamientos éticos se convierten en enfoques puramente pragmáticos o funcionalistas. Y la vida intelectual languidece, carente de inspiración y de acicates. Prescindir de lo que no tiene aplicación inmediata es muestra de estrechez de espíritu. En cambio, fomentar lo importante manifiesta generosidad y grandeza de las personas. Lo más importante para el ser humano es comprenderse a sí mismo. De eso, de la naturaleza y de la condición humana, es precisamente de lo que se ocupan las humanidades. Por lo que se infiera que la sociedad espera de la Universidad la capacitación y formación de profesionales de más alta calidad. 
En este sentido, se convierte en fundamental la formación humanista que, a toda actividad profesional, le da el rumbo, la orienta hacia la verdad para elegirla en función del bien común, para todos los seres humanos. En esta formación del profesional, es importante su dimensión ética y su conciencia social. Pero esta formación no se agota aquí, debe esclarecer problemas de índole política y cultural y convertirse en la conciencia moral de un país.

En la formación de muchos profesionales, las humanidades o la formación humanista, al estar ausente o aislada y no integrada en otras disciplinas confiriéndoles sentido y fin, no orientaron rectamente el ejercicio de la vida profesional de muchas personas, no formaron su inteligencia práctica. Por ejemplo, algunos profesionales solo se interesan por ocuparse de las clases altas que les van a generar mayores ingresos. Por este motivo, en la formación es necesario derribar los fines mercantilistas, contrarios a una genuina formación humanista, asume Alvira (2011).

Si estar formado con base humanista trae como consecuencia tantos aportes descritos anteriormente cabe preguntarse ¿̇cómo es percibida esta formación por los egresados de una universidad? Por eso se ahonda en esta percepción.

Siguiendo a During (2005), la percepción permite el conocimiento y el aprendizaje. De la percepción surge el recuerdo (memoria), de los recuerdos repetidos surge la experiencia, de la experiencia proviene el principio de la técnica y de la ciencia ya que no hay nada en la mente que no haya pasado por los sentidos, recuerda a Aristóteles. De la percepción nace la tendencia, pues donde hay percepción, también hay placer y dolor; donde están estos también hay apetito. En la percepción se dan tres grados: facultad, posesión, ejercicio. Para Leivas (2000), las percepciones son el resultado de la interpretación de las cosas, las personas, etc. Es un proceso mediante el cual las personas organizan e interpretan sus impresiones sensoriales para dar un significado a su entorno, hay una serie de factores que ayudan a dar forma o a distorsionar la percepción.

Estos factores pueden estar en cada ser humano, su historia, su interpretación, su expectativa, el objeto a percibir, el contexto y las circunstancias; por ello, como lo asume Vargas (2003) la percepción es un proceso cognitivo de la conciencia que consiste en el reconocimiento, interpretación y significación para la elaboración de juicios en función a las sensaciones obtenidas del ambiente físico y social, en el que intervienen otros procesos psíquicos entre los que se encuentran el aprendizaje, la memoria y la simbolización.

\section{Metodología}

El diseño de investigación utilizado se fundamenta en el enfoque cualitativo y el paradigma socio crítico, que al usar una metodología inductiva, sistemática y rigurosa permite describir las experiencias humanas tal como son vividas. Su propósito conlleva comprender e interpretar en profundidad la realidad, los significados y las intenciones para transformarla. El estudio se abordó con grupos focales, donde las opiniones vertidas permiten captar el sentir, pensar y vivir de los individuos, provocando auto explicaciones (Gibb, 1997; Aigneren, 2006)

Las y los sujetos de investigación fueron egresados y egresadas de las cinco facultades de la USAT, residentes en la Región Lambayeque, de ambos sexos, laboralmente activos. Se eligieron 32 entre egresadas y egresados en cuatro grupos focales, cada grupo con ocho integrantes de las diferentes facultades de la universidad bajo estudio y previo consentimiento informado. La muestra fue intencional, no probabilística y su tamaño se determinó, por saturación y redundancia. Sus identidades estuvieron protegidas utilizando códigos de identificación.

Se usó la entrevista semiestructurada grabada mediante mp3. Además, se aseguró a las y los participantes la confidencialidad de su identidad. El análisis de datos fue efectuado mediante el análisis de contenido. Se asume como criterios éticos los principios sustentados en la bioética personalista destacándose la libertad y responsabilidad, con criterios de rigor científico de credibilidad, audibilidad y la transferibilidad. 


\section{RESULTADOS Y ANÁLISIS}

Posterior al proceso y análisis de los datos recolectados en cuatro grupos focales constituidos por egresados de la USAT, emergieron cuatro grandes categorías con sus respectivas subcategorías que a continuación se detallan en la Tabla 1:

TABLA 1

Categorías y subcategorías que emergen de la investigación

\begin{tabular}{|c|c|c|}
\hline $\mathrm{N}^{\circ}$ & CATEGORÍA & Subcategoría \\
\hline I & $\begin{array}{l}\text { Preferencias } \\
\text { de los } \\
\text { egresados por } \\
\text { la USAT. }\end{array}$ & $\begin{array}{l}1.1 \text { Criterios } \\
\text { perceptivos de } \\
\text { elección. } \\
1.2 \text { Criterios } \\
\text { axiológicos de } \\
\text { elección. }\end{array}$ \\
\hline II & $\begin{array}{l}\text { Aportes del } \\
\text { aprendizaje } \\
\text { de las } \\
\text { humanidades } \\
\text { para el campo } \\
\text { laboral. }\end{array}$ & $\begin{array}{l}\text { 2.1Desarrollo } \\
\text { personal y } \\
\text { social para el } \\
\text { trabajo } \\
\text { 2.2 Desarrollo } \\
\text { de fe. }\end{array}$ \\
\hline III & $\begin{array}{l}\text { Experiencias } \\
\text { positivas y } \\
\text { negativas en } \\
\text { la Enseñanza } \\
\text { de las } \\
\text { Asignaturas } \\
\text { humanisticas }\end{array}$ & $\begin{array}{l}3.1 \\
\text { Experiencias } \\
\text { Positivas } \\
\text { 3.2Experiencias } \\
\text { Negativas }\end{array}$ \\
\hline IV & $\begin{array}{l}\text { Caracteristicas } \\
\text { del ejercicio } \\
\text { docente de } \\
\text { humanidades } \\
\text { propuesto por } \\
\text { los egresados }\end{array}$ & $\begin{array}{l}4.1 \\
\text { Conocimiento } \\
4.2 \text { Querer } \\
\text { 4.3 Hacer } \\
\text { 4.4 Convivir } \\
4.5 \text { Ser } \\
\end{array}$ \\
\hline
\end{tabular}

Fuente: Elaboración propia

\section{Categoría I: Preferencias de los egresados por la USAT.}

Las y los egresados denotan en sus declaraciones, su predilección por la USAT de acuerdo a sus percepciones.

\section{Criterios perceptivos de elección}

Los principios que inspiran a la USAT (búsqueda de la verdad al servicio de la sociedad, pluralismo y libertad de pensamiento respetando la propia axiología, defensa de la dignidad de la persona y desarrollo social integral), son captados por sus egresados, quienes al ser abordados en grupos focales reflexionan sobre la razón preferencial en elegirla entre otras universidades para cursar sus estudios profesionales, percibiendo su prestigio, fruto de varios fuentes de información como son la experiencia de amigos, familiares, la solicitud del mercado regional, la formación integral y humanista de sus estudiantes, así como la calidad de sus profesoras y profesores. 
...familiares, amigos y compañeros, todos señalaron que era la mejor opción porque es la más reconocida en el medio, y por sus logros alcanzados, una imagen de universidad ganada por ser exigente y a mí me gustan los retos... (M. Cervera, Comunicación personal Grupo Focal III, 4-10-2016)

...por su prestigio que tiene en la región de Lambayeque, como un de las mejores instituciones universitarias... (M. Cervera, Comunicación personal Grupo Focal II, 19-10-2016)

Las y los egresados direccionan sus respuestas, afirmando que optaron por la USAT, por la intervención de su familia, que quieren lo mejor para sus hijos e indagan la mejor forma de facilitarle la vida futura con la meta de verlos en un buen trabajo, un hogar, y con éxito. También señalaron que les gustan los retos:

... Por la trayectoria y reputación de la universidad algunas empresas suelen requerirnos...acabo de ingresar en el proyecto Olmos y me dicen si tienes otro compañero siempre y cuando sea de la USAT... (M. Cervera, Comunicación personal Grupo Focal IV, 30-12-2016)

...la experiencia que la universidad era de un excelente nivel... en el banco que trabajo siempre solicita que sea de la USAT...

(M. Cervera, Comunicación personal Grupo Focal I, 4-10-2016)

...ofrece una formación sólida y estaba reconocida...tuve una vacante en el internado y ahora varios trabajamos en hospitales, clínicas, centros de salud... (M. Cervera, Comunicación personal Grupo Focal II, 19-10-2016)

Desde la visión de las empresas eligen a sus nuevos empleados con base en la experiencia que han tenido con las y los egresados universitarios, si la experiencia es exitosa, requieren que estos sean de la misma universidad. La universidad es un factor importante en la contratación, ya que muchos egresados de instituciones de prestigio demuestran un buen nivel y esto hace que los empleadores deseen seguir incorporándolos a su personal (Bejarano, 2016). Además, los participantes del estudio afirmaron que eligieron a la USAT, por sus inquietudes profesionales, la obtención de una beca y la exigencia académica dada en la nota mínima de aprobación de asignaturas:

... la seleccioné... en esos años, una universidad que estaba en pleno crecimiento, la carrera profesional, con una estructura curricular basada en el cuidado humano... (M. Cervera, Comunicación personal Grupo Focal III, 24-11-2016)

...gané una beca de ingreso en la USAT y los consejos de los egresados de la misma, esto influyó mucho en mi decisión...

(M. Cervera, Comunicación personal Grupo Focal II, 19-10-2016)

...lo que la hace diferente es la investigación tanto a nivel del estudiante como del plan educativo, aprobábamos con $14 . .$.

(M. Cervera, Comunicación personal Grupo Focal IV, 30-12-2016)

La mayoría de participantes, dadas las exigencias actuales y la preferencia profesional optan por determinada universidad que le colme los anhelos de desarrollo y progreso. Según las apreciaciones de Llano (2003) que la fuerza de una universidad no procede de sus recursos económicos ni de sus apoyos políticos. El origen de su impacto se halla en la capacidad que sus miembros tengan de pensar con originalidad, con libertad y con energía creadora.

\section{Criterios axiológicos de elección}

Toda actividad universitaria, no solo se dirige al conocimiento instrumental- técnico profesional, sino el conocimiento superior de quien es su principal autor: La persona. Por ello se necesita conocerla en todas sus manifestaciones con visión integral; por ello en la universidad bajo estudio se imparten durante los cinco años de formación una serie de asignaturas humanísticas las cuales permiten saber, saber hacer y saber convivir entre personas, de tal manera que los universitarios y universitarias que manejan fácilmente estos saberes específicos les conduce a ser personas con criterios. Es necesario para la universidad que sus estudiantes aprendan a pensar, a razonar, a discutir, a no conformarse sino llegar hasta las convicciones más profundas y esto se consigue cuando existe prioridad con el conocimiento de la persona:

... La hizo diferente a las otras instituciones, la calidad en la educación sobre todo en valores, los cursos de teología 1,2, 3, moral cristiana. Doctrina social de la iglesia, antropología y demás me sirvieron de mucho en mi educación y también me 
sirvió de base para ejecutar ciertos dilemas en el trabajo y tomarlo con otra actitud... (M. Cervera, Comunicación personal Grupo Focal IV, 30-12-2016)

...formadora de profesionales éticos, con valores y responsabilidades en la sociedad y familiar, en mi actual trabajo, veo una serie de problemas que, si no hubiera recibido la formación recibida, no cabe diferencia... (M. Cervera, Comunicación personal Grupo Focal II, 19-10-2016)

Y además formaba en valores que era el motivo principal que la hacía diferente a las demás universidades de la región... (M. Cervera, Comunicación personal Grupo Focal I, 04-10-2016)

...me ayudó a desarrollarme y ser un buen profesional, creo yo, hasta este momento... (M. Cervera, Comunicación personal Grupo Focal III, 24-11-2016)

Las personas egresadas en conjunto evalúan, se percibe su sensibilidad al expresar sus sentimientos y emociones y a la vez hacen una valoración sobre la importancia de la educación en valores, porque experimentan en sus propias vidas el aprender a vivir. Además, la mayoría afirmó que llevar asignaturas de Doctrina social de la Iglesia, Antropología o Teología les ha servido para enfrentar problemas en sus centros de labores, tienen el convencimiento que su universidad forma profesionales éticos, que a través de sus acciones libres y voluntarias ejercidas con responsabilidad no solo en su centro laboral sino también en su familia y la propia sociedad donde viven:

...me sirvió mucho en mi formación por el empeño que me dieron mis docentes... (M. Cervera, Comunicación personal Grupo Focal III, 24-11-2016)

... mi familia es adventista, pero el prestigio y la sólida educación que brindaba se decidieron por la USAT, especialmente por la formación que imparte... (M. Cervera, Comunicación personal Grupo Focal IV, 30-12-2016)

...la diferencia primordial con el resto fue que ofrecía una formación sólida... (M. Cervera, Comunicación personal Grupo Focal I, 04-10-2016)

Por añadidura, la universidad, jamás debe perder de vista su vocación particular a ser una universitas, en la que las diversas disciplinas, cada una a su modo, se vean como parte de un unum más grande. Es muy urgente la necesidad de redescubrir la unidad del saber y oponerse a la tendencia a la fragmentación y a la falta de comunicabilidad que se da con demasiada frecuencia en las instituciones educativas (Ratzinger, 2007). Saberes que cada universidad asume de acuerdo a su visión y misión.

\section{Categoría II. Aportes del aprendizaje de las humanidades para el campo laboral.}

Fomentar los estudios de humanidades equivale a firmar la primacía del espíritu sobre la materia... lo que equivale a renunciar al hallazgo de lo nuevo, cuya fuente, como ya sabemos, no es otra que el propio espíritu (Ratzinger, 2007). Según las apreciaciones de Llano (2003), el creciente abandono de las asignaturas humanísticas deteriora el dominio del lenguaje, dificulta la comunicación entre personas de diversas convicciones, culturas o niveles sociales afectando la capacidad de la deliberación en cuestiones prudenciales, que constituye la espina dorsal de la actividad política.

\section{Desarrollo personal y social para el trabajo}

Las personas egresadas ya profesionales perciben de manera progresiva sentirse diferentes a como ingresaron en un año determinado a sus estudios universitarios, crecimiento que asumen en bien de los demás, el sentido que tenía estudiar determinada carrera y en su propio bagaje cultural. Al respecto, Polo (2007) afirma que el ser humano es un ser que crece, nace débil, sin haber desarrollado plenamente su organismo, sus facultades a quien hay que ayudarle a crecer. Y para crecer requiere ser ayudado por otras personas, no en pos de la adaptación al medio, sino de la aportación que debe hacer al medio social. Los egresados manifestaron: 
... Amplió mi abanico cultural, me hizo más empática al momento de atender al público y darme cuenta que todo lo que hago es para el bienestar de los demás de conocer más sobre la persona y como debe actuar en la sociedad rigiéndose por valores y la ética que hoy en día están perdidos... (M. Cervera, Comunicación personal Grupo Focal III, 24-11-2016)

... Nos ayudó a darle otra visión a la carrera, no solamente lo científico, sino también el lado humano, que nos ayuda a desarrollarnos como personas, fueron asignaturas que calaron en mi personalidad, me han ayudado a desenvolverme mejor al momento de postular a una vacante, corregir algunos comportamientos, a luchar por cumplir mis objetivos, dedicarme a la familia, ayudar a los amigos y compañeros, dentro de mi centro de trabajo... (M. Cervera, Comunicación personal Grupo Focal II, 19-12-2016)

... creo que me han ayudado a desarrollarme de una mejor forma en todos los ámbitos de mi vida, a ser más optimista, a no ver mi carrera como una forma de ganar dinero, sino también de contribuir con mi ciudad... (M. Cervera, Comunicación personal Grupo Focal IV, 24-11-2016)

... Percibí con claridad mi naturaleza y mi fin en la humanidad y porque estudiar mi carrera... (M. Cervera, Comunicación personal Grupo Focal I, 04-10-2016)

Llano (2012) declara que cada estudiante es un ser humano que tiene fe en que por medio del estudio y de la ampliación de sus conocimientos va a mejorar y enriquecer su naturaleza y condición humana, no en cantidad, sino en calidad, va a volverse más persona, mejor persona, y a cumplir mejor su destino, va a entender mejor los problemas que le rodean y tratará de solucionarlos. Lo que hay que fomentar en el alumnado es ese valor vital de la cultura, esa confianza en su capacidad para mejorar siempre.

\section{Desarrollo de la fe}

Las asignaturas de Antropología filosófica y Teología llevaron a las personas egresadas hacia la apertura de su espíritu. Aluden su interés en el aspecto espiritual, por eso llegan a la comprensión de la fe que profesan como un don recibido. La fe es un acto humano, pues no es contrario ni a la libertad ni a la inteligencia del ser humano depositar la confianza en un ser supremo. Criterios también expresados por los egresados:

... me permitió afianzar mi fe, conocer a Dios por medio de la razón...comprendí mi fe como un don de dios... (M. Cervera, Comunicación personal Grupo Focal I, 04-10-2016)

... sobre todo conocer la relación entre los seres humanos y Dios. Dado que no solo es importante enriquecer el aspecto profesional, sino también espiritual... (M. Cervera, Comunicación personal Grupo Focal II, 19-10-2016)

Las personas egresadas haciendo uso de su racionalidad son capaces de comprender la necesidad del cuidado del espíritu, que junto con el cuerpo forman al ser humano como una realidad unitotal, trascendente, capaz de coexistir con el universo, con los otros y también con el Absoluto.

\section{Categoría III. Experiencias positivas-negativas en la enseñanza de las asignaturas humanísticas}

Las personas egresadas de la USAT, al ser abordadas sobre la enseñanza de las asignaturas humanísticas para dejar huella en el campo laboral destacaron varias cualidades efectivas y reales, cabe destacar que se les observó optimistas cuando hablaban con actitud constructiva frente a sus experiencias asertivas, pero también explicaban aspectos negativos al notar carencias, vacíos al momento de recibir las sesiones de aprendizaje.

\section{Experiencias positivas que tuvieron las personas egresadas en las sesiones de humanidades}

Las personas egresadas manifestaron que las asignaturas humanísticas fueron provechosas y les resultaron beneficiosas porque sus enseñanzas fueron factibles tanto en lo personal y en lo profesional. Nussbaum (2010) considera que la enseñanza de las humanidades es vital para cualquier persona y, muy específicamente, para las 
y los estudiantes universitarios, pues dichos saberes aportan al desarrollo de la sensibilidad, la fraternidad y la imaginación. Las humanidades no son la decoración de una disciplina, sino parte constitutiva de un proyecto formativo. A ellas se les debe dar igual importancia como se les asignan aquellas otras materias consideradas las principales de un programa académico.

Cabe mencionar que en el modelo educativo USAT uno de sus ejes formativos está la formación humana cristiana, por ser una universidad católica proporciona una formación basada en los principios de defensa y desarrollo de la dignidad de la persona humana, dicha formación está presente en todas las carreras universitarias. Parte de esa formación lo constituyen la enseñanza de las humanidades entre ellas la filosofía, teología, historia, ética, la bioética entre otras, asignaturas que conectan utilidad para la vida personal y profesional de las y los egresados. Así lo expresan:

... para nosotros fue provechoso y tratamos de absorber todo lo que recibimos, al principio no los valoras, por la exigencia de trabajos, pero cuando estas fuera de la universidad, solo estás tú y los conocimientos recibidos para demostrar al mundo lo que eres y lo eres capaz de hacer... (M. Cervera, Comunicación personal Grupo Focal III, 24-11-2016)

... me permitió analizar las cosas de manera objetiva y razonable...en valores para conducirme, la ética que se debe aplicar en el trabajo y el trabajo de equipo con los compañeros de trabajo...este último a saber esperar, ahora no saben cómo son útiles... (M. Cervera, Comunicación personal Grupo Focal IV, 30-12-2016)

... reforzó mis conocimientos, para saber diferenciar entre lo bueno y lo malo, acerca de la dignidad de la persona de los seres humanos y tener en cuenta que nuestras acciones traen consigo, consecuencias que pueden repercutir en nuestro entorno..., si mientes, engañas o murmuras...tú mismo cómo te sientes...mal...muy mal y aprendí a rectificar... (M. Cervera, Comunicación personal Grupo Focal II, 19-10-2016)

... los temas siempre eran llevados o incluidos con la formación profesional, me sirvió permitió ponerlo en práctica... aunque cuesta bastante... (M. Cervera, Comunicación personal Grupo Focal I, 04-10-2016)

Las personas egresadas dan cuenta cómo la enseñanza de asignaturas humanísticas les permiten ver el mundo como es, cómo es la realidad de las cosas de forma serena, equitativa, porque han adquirido un grado de conocimiento que les permite discernir sobre la realidad que viven y esto gracias a su capacidad crítica.

También perciben como se van desempeñando en el trabajo con valores éticos, el trabajo de equipo con los demás y saber distinguir en sus acciones libres aquellas que son virtuosas de aquellas que son viciosas, además las personas bajo estudio fueron conscientes en la manera cómo las propias acciones tienen repercusiones en ellos mismos y en el ambiente donde trabajan, es decir consecuencias que de alguna manera influenciarán en su futuro profesional.

\section{Experiencias negativas que tuvieron las personas egresadas en las sesiones de humanidades}

Participantes en el estudio asumieron que era necesario cambiar la manera como se enseñan las asignaturas de humanidades, pues si siguen dándose como las dejaron no habrá cambios importantes. Dada esta circunstancia, ambos señalaron algunas experiencias consideradas negativas en las asignaturas de humanidades: señalaron metodologías rutinarias con exceso en la teoría y poca transferencia a la carrera profesional relacionado con el profesorado que enseña, pues "no conoce la carrera que llevamos" (M. Cervera, Comunicación personal Grupo Focal IV, 30-12-2016) se afirmó en algún momento. Solicitando se busquen alternativas para mejorar la manera de enseñar estas asignaturas. Manifestaron como negativo el uso de metodologías poco dinámicas o rutinarias:

... algunos docentes les falta desarrollar el curso de manera dinámica para que sea más amena... (M. Cervera, Comunicación personal Grupo Focal IV, 30-12-2016)

... más dinamismo, que se enfoque en hacer comprender que toda persona no es solo un ser excelente en los estudios sino que también busque ser buena persona... (M. Cervera, Comunicación personal Grupo Focal II, 19-10-2016)

Lo distinguido por las personas entrevistadas son situaciones percibidas en el aula; como receptores de la enseñanza cuestionan debilidades en la metodología de la enseñanza de las asignaturas humanísticas de 
una parte del cuerpo docente: pasividad, inadecuado uso de las TIC como diapositivas lleno de párrafos solo leídos, entre otros aspectos negativos. Polo (2009) expresa que el personal docente universitario que utilice apuntes que él mismo se ha hecho, siendo los mismos todos los años, es señal de su falta de autenticidad y compromiso vocacional, revela pereza y nulidad investigativa.

Sin embargo, existe la posibilidad de que algunos profesores continúen usando la enseñanza bancaria donde el estudiantado es un simple receptáculo pasivo, que repite dócilmente los esquemas dados en clase, memoriza y almacena una serie de datos que conducen al conformismo (Domínguez, 2006).

Igualmente, las personas entrevistadas detallaron que a varios profesores les hacen falta desarrollar las asignaturas humanísticas de manera más eficiente para que así resulte ameno aprender, que busque motivarlos, siendo un elemento vital para el desarrollo de sesiones didácticas en todos los niveles y más aún en la universidad. La falta de estímulos, el estancamiento intelectual y el bajo perfil de muchos docentes son factores que influyen en la calidad de la educación.

Otra experiencia considerada negativa por egresados y egresadas respecto a la enseñanza de las humanidades es el exceso de teoría y asignaciones extensas de trabajo, olvidando que de lo que se trata es de que sea una auténtica experiencia de aprendizaje, asumiéndose de manera consiente y voluntaria. Ellas y ellos lo evidencian:

... asignaturas con mucho peso y cargaban trabajos, eso distraía el tiempo para las asignaturas que eran de la carrera... (M.

Cervera, Comunicación personal Grupo Focal I, 04-10-2016)

... muy teóricos, me gustaría, más prácticos y dinámicos... (M. Cervera, Comunicación personal Grupo Focal IV, 30-12-2016)

$\mathrm{Al}$ respecto, no poco personal docente universitario conoce la existencia de herramientas online, muy buenas para contribuir, con sus espacios virtuales a estimular el aprendizaje previo y poner en marcha clases dinámicas donde el alumnado acude a clase habiendo ejecutado anticipadamente diversas actividades, de forma que antes de recibirlas ya tiene un aprendizaje previo y acude al aula para completar su conocimiento. Para una correcta enseñanza práctica y dinámica como ideal es necesario hacer una combinación con técnicas tradicionales y metodologías más innovadoras, por ejemplo, haciendo uso de TIC, o descubriendo las bondades académicas de internet. Además, el uso de metodología activa existe una combinación de prácticas teatrales, enseñanza basada en problemas, resolución de casos, y prácticas vivenciales o simuladas.

Finalmente, también consideran como una experiencia negativa la escasa transferencia práctica a las carreras, pues según ellas y ellos no visionaban consecuencias prácticas; otros alegan que la teoría parece tomar muy poco en cuenta las situaciones de sus propias carreras:

... algunos compañeros no les agradaban estos cursos, pues no tenían que ver con la carrera o los estudios que estábamos

llevando en ese momento... debe darse una por ciclo... (M. Cervera, Comunicación personal Grupo Focal III, 24-11-2016)

... sentimos en algún momento que restaban tiempo a mi formación, los cursos deben relacionarse más con la carrera que

lleve...eran muy pesadas y cargadas de estudio, eran cursos obligatorios en la malla curricular (M. Cervera, Comunicación personal Grupo Focal II, 10-11-2016)

$\mathrm{Al}$ respecto, el personal docente debe estar preparado para hacer uso de variadas estrategias didácticas donde el estudiantado participe activamente en su aprendizaje, especialmente cuando se trata de asignaturas humanísticas.

Llano (2006) advierte que la formación humanística confiere hondura a las profesiones. Con las humanidades enseñadas a través de asignaturas humanísticas, el alumnado llega a aprender los sucesos de la vida cotidiana con un enfoque diferente, comprender las necesidades de los demás. Por ello su enseñanza debe proporcionar deleite, con ganas de asimilarlas y practicarlas y de esta manera todos aprendan a resolver la variedad de situaciones conflictivas personales, familiares y también las que involucran a la sociedad cada vez más pluralista (Prevost, 2016). En consecuencia, estudiantes y docentes deben revitalizarse para desterrar la monotonía en la enseñanza de las humanidades, mejorando los métodos didácticos. 


\section{Categoría IV. Exigencias docentes propuestas por las personas egresadas para desarrollar asignaturas humanísticas.}

Todas las personas egresadas bajo estudio aportaron desde sus percepciones cómo deberían ser desarrolladas las asignaturas humanísticas debidas su importancia en el campo laboral: Que el profesorado que las enseña responda a un perfil exigente para que la forma de enseñanza cambie y no se continúe con la rutina pedagógica que vivenciaron.

La sociedad del futuro exigirá al cuerpo docente universitario ser creador del conocimiento superior, pues los tutelados como estudiantes o personas egresadas se enfrentarán a situaciones difíciles y complejas tales como: concentración de poblaciones de alto riesgo, diversificación cultural del público universitario, grupos extremadamente heterogéneos, multiplicación de diferentes lugares de conocimiento y de saber, acceso a puestos en forma provisoria, rápidas y permanente evolución cultural y social especialmente en jóvenes en quienes existe la sensación de que no hay futuro y una suerte de pérdida del sentido del saber o el aprender.

Por su parte, el modelo USAT exige a educadores de universidades el dominio de varios enfoques pedagógicos que se adecuen a los cambios generacionales del estudiantado en lo social, tecnológico, laboral, entre otros. Ahora bien, los egresados señalaron una serie de exigencias para los docentes de asignaturas humanísticas en los siguientes pilares señalados:

Conocimientos: Dominar la materia que enseña, sabiendo aplicarla a distintos contextos y circunstancias, con postgrado y amplia cultura profesional:

... Con maestría en algún curso humanístico... (M. Cervera, Comunicación personal Grupo Focal III, 24-11-2016)

... Conocimientos profundos en antropología, ética, moral y filosofía... (M. Cervera, Comunicación personal Grupo Focal II, 19-10-2016)

... Contar con conocimientos teóricos amplios y experiencia laboral extendida... (M. Cervera, Comunicación personal Grupo Focal IV, 30-12-2016)

... Conozcan de los temas a tratar y absuelven cualquier duda... GFI ... Investigación antes de dar clase... (M. Cervera, Comunicación personal Grupo Focal II, 19-10-2016)

Las personas egresadas asumen que el profesorado que enseñe asignaturas humanísticas debe contar con postgrado, porque tienen experiencia en investigación y ejercen mucho mejor su docencia. En el caso de las asignaturas humanísticas cada docente debe dominar la materia que enseñan, con dominio metodológico y didáctico, porque el nivel de enseñanza es de conocimiento superior.

Las exigencias en el querer que señalan las y los egresados requiere que cada docente que enseña humanidades tenga la capacidad de desarrollar su intersubjetividad que le permitirá develar cómo se es, y ello requiere esfuerzo y voluntad para comprometerse con la propia formación y del estudiantado asignado, y esta acción requiere constancia. Una motivación de carácter trascendental, mantiene niveles altos, aun cuando las recompensas externas disminuyan o desaparezcan.

... Personas con mucha capacidad de reflexiones profundas y carismáticas... (M. Cervera, Comunicación personal Grupo Focal I, 04-10-2016)

... Que proyectan entusiasmo, seguridad... (M. Cervera, Comunicación personal Grupo Focal IV, 30-11-2016)

... Proporcionen confianza necesaria para recurrir a ellos y brindan su amistad... (M. Cervera, Comunicación personal Grupo Focal II, 19-10-2016)

Las personas egresadas quieren que se preocupen por ellas, para que los conocimientos lleguen a calarles la vida, de tal forma que tengan seguridad en lo que hacen y dicen, y no haya ambivalencias entre el decir y el actuar, forma parte de la magnanimidad la confianza en sí mismo para todas aquellas cosas que uno es capaz de hacer.

El saber hacer está relacionado con las competencias procedimentales adaptadas a los contextos cambiables con capacidad de iniciativa. En este sentido, señalaron que el personal docente que enseñe asignaturas 
humanísticas deben ser de una edad apropiada, que tenga años en experiencia profesional, y no sea un egresado o egresada reciente de la universidad, por ser demasiado joven y carecer de experiencia en la enseñanza de las asignaturas humanísticas:

...Edad media, no muy joven... (M. Cervera, Comunicación personal Grupo Focal II, 19-10-2016)

...Utilizar una metodología dinámica, que permita llegar a los estudiantes... (M. Cervera, Comunicación personal Grupo Focal II, 19-10-2016)

Los primeros en dominar sus metodologías deben ser las profesoras y profesores que enseñan humanidades declararon las personas egresadas porque sus enseñanzas deben calar para bien: la huella que dejó sus enseñanzas prácticas, modos como resolver problemas y especialmente el ejemplo docente debe ser el referente profesional.

Respecto al saber convivir, otra exigencia reclamada y percibida por las y los egresados estuvo relacionada en la manera como los docentes se relacionan con los estudiantes en el día a día de las sesiones, sobre la existencia de un clima amigable en el aula. Algunos de los entrevistados refirieron que era preferible que las asignaturas sean enseñadas por sacerdotes por ser personas con quienes es fácil conversar, hablar de sus problemas, sintiéndose mejor comprendidos, mientras que un profesor a veces solo se limita a pedir trabajos y exposiciones y no los escucha:

...Debe ser un sacerdote porque te brinda más confianza y así poder dialogar y solucionar problemas... (M. Cervera, Comunicación personal Grupo Focal IV, 30-12-2016)

...Fomente el respeto y la puntualidad... (M. Cervera, Comunicación personal Grupo Focal III, 24-11-2016)

En este sentido el buen convivir en el aula o en cualquier espacio académico universitario exige al docente fomentar actitudes de respeto, tolerancia y las y los compromete en sus valores, actitudes, metodologías y prácticas.

Respecto al saber ser, los egresados, consideraron que los profesores y profesoras que enseñen asignaturas humanísticas deben ser personas excelentes que motiven a las y los estudiantes a ser responsables y solidarios entre ellos, la familia, la propia sociedad:

...Una persona que practique los valores éticos y que las demuestre en clase con los alumnos y que explique adecuadamente...

(M. Cervera, Comunicación personal Grupo Focal IV, 30-12-2016)

...Excelentes personas en la convivencia universitaria... (M. Cervera, Comunicación personal Grupo Focal I, 04-10-2016)

Educar lleva consigo un sentido de participación en aquello que se quiere transmitir; no está pendiente de modo exclusivo de las calificaciones, de ese número frío que refleja los conocimientos empaquetados en la memoria estudiantil. El educador ha de educar si quiere ser considerado como tal.

\section{CONSIDERACIONES FINALES}

Las personas egresadas de la universidad peruana bajo estudio la prefirieron por criterios perceptivos y criterios axiológicos. Entre los perceptivos destacaron la predilección de las empresas por los egresados de la universidad, su excelente nivel y la formación sólida que imparte. Y como criterios axiológicos enfatizaron ser generadora de profesionales éticos con responsabilidad en la vida social y familiar que ayudan a resolver problemas en el campo laboral.

Las personas egresadas percibieron que la enseñanza-aprendizaje de asignaturas humanísticas les ha permitido su crecimiento personal y social en el propio campo laboral, así como en la vivencia de su fe, enriqueciendo de esta manera su dimensión espiritual.

Las personas egresadas, que tuvieron entre 5 y 7 años de formación en la USAT, expresaron sus experiencias tanto positivas y negativas respecto a la enseñanza de las asignaturas humanísticas. En lo positivo mencionaron que ellas son útiles y aplicables, además les ayudó a muchos a reflexionar sobre acontecimientos 
personales, sociales y familiares para tomar decisiones. Como experiencias no positivas señalaron que muchas veces la enseñanza de las humanidades era abordada con metodologías poco dinámicas con exceso de teoría y asignaciones de tareas con escasa transferencia para la propia carrera que seguían.

Las personas egresadas consideraron que el personal docente que enseñe humanidades debe reunir ciertos requisitos como experiencia, estudios de postgrado, estrategias didácticas activas, entre otros, para evitar que la rutina y el tedio les domine de tal manera que sean asignaturas que se anhele estudiar y practicar. Las exigencias están enmarcadas dentro del conocer, querer, hacer, convivir y ser.

\section{ReFERENCIAS}

Aigneren, M. (2006). La técnica de recolección de información mediante los grupos focales. Recuperado de https://bit. ly/2PPXT4t

Amarcha, A, Cristóbal, A. y Castro, L. (2005). Tendencias de las trayectorias de los titulados en tránsito al mercado laboral. International Journal of Psychology and Psychological Therapy, 5 (3), 233-245.

Aldana, A. (2009). Formación humanística del estudiante universitario. Studiositas, 4(3), 9-20. Recuperado de https ://dialnet.unirioja.es/descarga/articulo/3658899.pdf

Alvira, R. (2006). Humanidades para el Siglo XXI. Pamplona, España: EUNSA.

Alvira, R. (2011). Apuntes de Principios de Filosofía Politica. Pamplona, España: Eunsa.

Bejarano, L. (2016). ¿Qué tanto influye el prestigio de la universidad al buscar empleo? Colombia: Universidad Colegio Mayor de Cundinamarca.

Domínguez, X. (2006). Ética del docente. Málaga, España: Fundación Emmanuel Mounier.

During, I. (2005). Aristóteles: Exposición Interpretación de su pensamiento. México: UNAM - IIF.

Gibb, A. (1997). Focus group. Social Research Update, 5(2), 1-8. Recuperado de: http://sru.soc.surrey.ac.uk/SRU19 .html

Leivas, E. (2000). La Percepción de la personalidad un concepto. Madrid, España: Días De los Santos S.A.

Llano, A., Alvira, R., Calleja, T. Bastons, M. y Martínez, C. (1992). El Humanismo en la Empresa. Madrid, España: Rialp.

Llano, A. (1998). La nueva sensibilidad. Madrid: Espasa Calpe.

Llano, A. (2003). Repensar la Universidad. La Universidad ante lo nuevo. Madrid, España: EIUNSA.

Llano, A. (2006). Sentido actual de las humanidades. R. Alvira, Humanidadespara el Siglo XXI. (pp. 47-60). Pamplona: EUNSA.

Llano, A. (2012). ¿Ocaso de las Humanidades? Revisiones, 7, 185-192. Recuperado de https://bit.ly/2Eta2F8

López, M. (2009). Efectos de la correspondencia entre educación y empleo de los jóvenes en el mercado de trabajo mexicano. RMIE, 14(42), 863-887.

Martínez, J. (2009). Filosofía y Lenguaje: La formación Humanistica en el desarrollo personal y sociocultural. (Tesis doctoral). Universidad Complutense de Madrid, España.

Nussbaum, M. (2010). Sin fines de lucro. Por qué la democracia necesita de las humanidades. Madrid: Katz editores.

Pizzul, M. (2013). La formación humanistica fin esencial de la universidad. Mar del Plata, Argentina: Universidad Fasta.

Polo, L. (1997). Ética. Hacia una versión de los temas clásicos. Madrid: Aedos-Unión.

Polo, L. (2007). Ayudar a crecer. Cuestiones filosóficas de la educación. Pamplona, España: EUNSA.

Polo, L. (2009). El profesor Universitario. Piura: UDEP

Prevost, R. (2016, abril). La Universidad Católica Santo Toribio de Mogrovejo: 18 años al Servicio de la Educación. Discurso como Gran Canciller de la USAT. Discurso presentado en Chiclayo, Perú.

Ratzinger, K. (2007). Discurso del Papa Benedicto VXI a profesores Universitarios de Europa. Recuperado de https:// bit.ly/30DJMRJ 
Reluz, F. (2014). Filosofía que debe permanecer en la Educación Actual. Lima, Perú: IIPCIAL.

Ruiz, M. (2002). Las humanidades como experiencia de comprensión en la formación universitaria. Revista de educación y pedagogía, 14(34), 69-82.

Sellés, J. (2007). Antropología para inconformes. Madrid: Rialp.

Stramiello, C. (2005). ¿Una educación humanista Hoy? Revista Iberoamericana de Educación 36(8): 1-5. Recuperado de http://www.rieoei.org/deloslectores/1031Stramiello.PDF

Solís, F. (2010). La formación humanista, la universidad y la sociedad del conocimiento. Red Universidades Anábuac. Recuperado de https://bit.ly/2EWUgCm

USAT. (2009). Estatuto Universidad Católica Santo Toribio de Mogrovejo. Chiclayo, Perú: Fondo Editorial Universitario.

USAT. (2011). Modelo educativo Universidad Católica Santo Toribio de Mogrovejo. Chiclayo, Perú: Fondo Editorial Universitario.

Vargas, J. (2010). De la formación humanista a la formación integral: reflexiones sobre el desplazamiento del sentido y fines de la educación superior. Revista Praxis Filosófica, 30, 145-167. Recuperado de https://bit.ly/2K27jqi

Vargas L. (2003). La percepción como un proceso cognitivo. Buenos Aires, Argentina: Macchi Grupo.

\section{BY-NC-ND}

